\title{
Cyclotron production of medical isotopes scales up
}

$\mathrm{F}$ ive years after a cranky old nuclear reactor put Canada's medical community on notice that its supply of a key radioisotope was no longer secure, investigators have declared an entirely different source ready for prime time. Cyclotrons, once relatively obscure pieces of lab research equipment, are poised to displace the reactor as Canada's optimal source of technetium 99, the radioactive staple of modern medicine.

Some 30 hospitals across the country house cyclotrons. On June 9, a team in Vancouver, British Columbia, demonstrated how a single cyclotron operated by the BC Cancer Agency can produce enough technetium to meet the SPECT (single photon emission computed tomography) needs of the Vancouver metropolitan area.

"It was surprisingly simple," says Francois Benard, one of the research team's principal investigators, who holds a research chair in functional cancer imaging at the cancer agency. "We really feel we have a good understanding of the issues and a good solution in the works to make this a viable process."

Hospital cyclotrons have long been able to produce modest amounts of technetium for laboratory purposes, but now it has been shown that this same capability can be augmented to deliver technetium in amounts that could serve large parts of the country.

"We know we can make it reliably. And we're still working on the final model of how this would be implemented," says Benard.

Paul Schaffer, head of the Nuclear Medicine Division at TRIUMF, a national physics research laboratory in Vancouver, believes the scale-up will continue. "We can supply British Columbia with the infrastructure that we have in place already," he says.

Natural Resources Canada has invested almost $\$ 60$ million to encourage research teams — including Benard's - to find ways of producing the isotope without investing in new equipment. Cyclotrons in hospitals across Canada are a real contender.

This summer, Edmonton is launching a new cyclotron that is larger than its existing one at the Cross Cancer

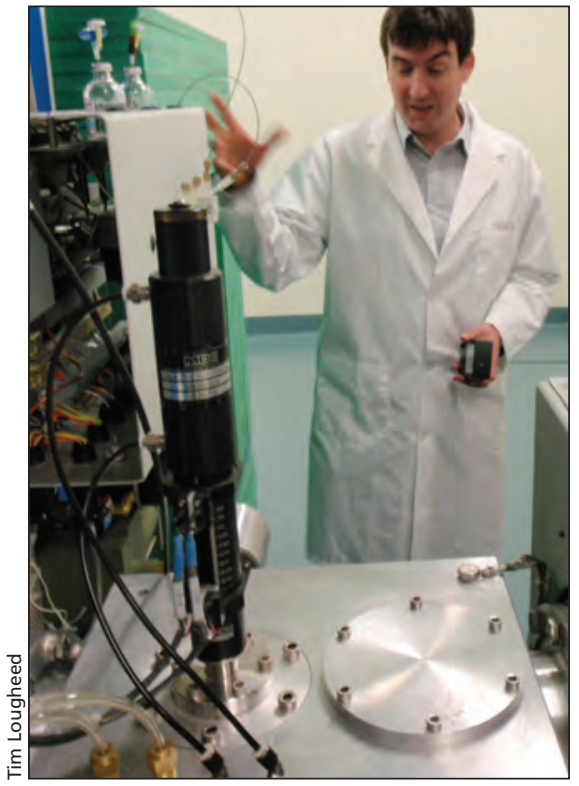

According to researcher Francois Benard, this cyclotron can produce enough technetium to meet the need for single photon emission computed tomography in the Vancouver metropolitan area.

Institute. According to John Wilson, who manages the Edmonton PET Centre, the two devices should readily meet all the technetium needs of Alberta.
"With seven or eight of these across the country, we could produce $90 \%$ of the needs of Canada," he says.

Progress has also been made on a cyclotron pair in Quebec, at the Centre Hospitalier Universitaire de Sherbrooke-Hôpital Fleurimont. Eric Turcotte, a clinician-researcher there who has been on the front lines of this issue since the Chalk River reactor breakdown, can foresee how just a few of these machines could meet the province's technetium needs.

In the meantime, Turcotte and other researchers anticipate the challenge of meeting Health Canada Good Manufacturing Practice regulations. Administrators at cyclotron facilities are already coming to grips with this challenge. And since the Chalk River reactor is officially set to get out of this business by 2016, people like Schaffer are not ready to relax and count their isotopes.

"We've got to keep our nose to the grindstone," he says. — Tim Lougheed, Ottawa, Ont.

CMAJ 2013. DOI:10.1503/cmaj.109-4525

\section{More news online}

Federal Wi-Fi panel criticized for undisclosed conflict: The Royal Society of Canada will reconsider its decision to appoint a University of Ottawa professor to chair a panel it convened to assess the safety of radiowave-emitting devices such as cellular phones, following a CMAJ investigation that reveals a potential conflict-of-interest. - Paul Christopher Webster, Toronto, Ont.

Reproductive health experts warn women not to abandon birth control: Leading members of the Canadian medical community fear women will panic, stop taking birth control pills and become pregnant if they abandon the popular oral contraceptives Yaz and Yasmin amid reports of deaths and class-action lawsuits. - Janice Tibbetts, Ottawa, Ont.

US Drug strategy runs counter to Canada's: A new US drug control strategy to increase treatment and reduce incarcerations is at odds with the Harper government's drive to imprison more Canadians for drug offenses, Canadian drug policy analysts say. — Paul Christopher Webster, Toronto, Ont.

International consortium unveils scores of new cancer genetic markers: The largest genome-wide study focused on oncology has discovered 74 new genetic variants linked to breast, ovarian and prostate cancers. Amanda Alvarez, Berkeley, Calif.

CMAJ 2013. DOI:10.1503/cmaj.109-4542 cmaj.ca 